\title{
NAS ÁGUAS TURVAS DO POEMA: A EXPERIÊNCIA LITERÁRIA MANOEL DE BARROS
}

Cynthia de Cássia Santos Barra*

RESUMO:

Este ensaio pretende ler a obra de Manoel de Barros, tendo como suporte teórico as reflexões de Maurice Blanchot sobre a experiência literária.

PALAVRAS-CHAVE: poesia, estilo, experiência literária.

0 que estamos por descobrir ao lermos uma poesia que parece afirmar-se reafirmando-se pela repetição e que a cada novo livro vem se tornando um espaço aberto a velhos e rasurados versos? Passados mais de 60 anos entre a primeira e a mais recente publicação de Manoel de Barros, deparamo-nos, a cada novo livro, com a repetição. Essa repetição paciente e cuidadosa de temas, de figuras, de ritmos, de versos, por vezes inteiros, tem requerido seu espaço e o constrói com bordas e fim. Desde quando isso? Movido por quê?

É conhecida a opinião de Carlos Drummond de Andrade: "No início da carreira, o escritor plagia autores; no fim, a si mesmo". Assim, para Barros, segundo alguns críticos que lêem sua obra, atentos aos desenvolvimentos de sua poesia, teria chegado, então, o tempo de viver sob a sombra desse mau agouro vaticinado por Drummond. Sanches Neto, que em 1997 escreveu um livro - Achados do chão - sobre a importância da palavra submersa de Barros em certo momento de redefinição da poesia nacional (ainda na primeira metade do século XX), após o lançamento de um dos últimos livros do poeta, reconsidera:

Mero pastiche de si mesmo, o Manoel de Barros de Retrato do artista quando coisa (Record, 1998) não consegue se distinguir das centenas de copistas que * Mestre em Letras: Estudos Literários (Área de concentração: Literatura Brasileira), 2000. 


\section{EM TESE}

Belo Horizonte, v. 5, p. I-305, dez. 2002

têm desvalorizado o seu estilo no mercado das artes. (...) Tradicionalmente, Manoel de Barros se impôs por propor um texto que assumia a contribuição milionária de todos os erros. 0 seu verbo deformante entrou na poesia brasileira, marcada pelo cerebralismo cabralino e vanguardeiro, como uma voz dissonante. (...) Foi por romper com a visão asséptica, formalmente equilibrada, que ele conquistou uma posição central na lírica brasileira. E seu papel histórico não pode ser ignorado. (...) 0 poeta não percebeu que sua poesia, nos últimos dez anos, foi perdendo a cada livro a atualidade. (...) Tudo em Retrato de artista quando coisa tem cara conhecida. São os mesmos elementos de outros livros (...) (Sanches Neto, 1998).

Segundo Sanches Neto, não podemos esquecer a importância histórica da poesia de Manoel de Barros no contexto da poesia brasileira em geral; mas, agora, é a isso, apenas, que deve ser referido o seu valor. Desatento, repetitivo, nebuloso, monótono, enfim, o poeta despede-se, por meio de uma espécie de escrita que vai de mau a pior, da poesia de qualidade, ainda que 1he restem alguns poemas.

Nos domínios da cultura literária, em seus muitos discursos, parece fácil, corriqueiro mesmo, encontrar exemplos dessas firmes manifestações que buscam salvaguardar o novo, o virtuosismo, a originalidade do que é dito pela primeira vez. Tenta-se assinalar, assim, aqueles que devem permanecer, espécie de vencedores, no êxito e na nossa memória. Se nos distanciássemos desses propósitos, o que nos restaria a dizer? 0 que desistiríamos de dizer?

Mesmo aquilo que um dia pôde ser visível e valorizado justamente por assumir a contribuição milionária de todos os erros não deve ir longe demais em seu gesto errático, deve manter-se fiel à literatura como excelência, evitando, a todo custo, sucumbir ao obscuro encontro que pode fazer do novo, retorno; do nada, tudo; do sucesso, fracasso; do erro, verdade; e de cada um desses, sucessiva e indiscriminadamente, o seu oposto, um perigoso (indomável?) oposto, porque, finalmente, sem oposição. E aqui, nesse ponto, não haveria mais sentido para fazer cessar a errância. Escrever de mau a pior para escrever cada vez melhor o que desde sempre esteve lá? Sim, lemos Barros nesses descaminhos de infinita deserção. Como diz Clarice Lispector:

Por que publicar o que não presta? Porque o que presta também não presta. Além do mais, o que obviamente não presta sempre me interessou muito. Gosto de um modo carinhoso do inacabado, do malfeito, daquilo que desajeitadamente tenta um pequeno vôo e cai sem graça no chão. (Lispector, 1999: 6) 
Assim como Clarice Lispector, os versos de Barros, é sabido, gostam do malfeito, do que não presta, dos caídos no chão, todos esses "relevos do insignificante" (Matos, 1992). Esse é um dos motes e uma das formas insistentes de sua poesia. Seus poemas dizem o inacabamento:

Depende a criatura para ter grandeza de sua infinita deserção.

A gente é cria de frases. Escrever é cheio de casca e pérolas.

Ai, desde gema sou borra!

Alegria é apanhar caracóis nas paredes bichadas.

Coisa que não faz nome para explicar

Como a luz que vegeta na roupa do pássaro. (Barros, 1996: 211)

Acabamos de citar o canto XIII, de um extenso poema intitulado "Sabiá com trevas". Esse canto, de maneira semelhante a muitos outros escritos de Barros, traz-nos, pela força do inacabamento, algo de seus rascunhos $\frac{3}{4}$ aqueles "mínimos bloquinhos rabiscados" (Castello Branco, 2000) que o poeta há tempos guarda consigo:

Nas gavetas da escrivaninha estão guardados os incontáveis caderninhos que ele próprio confecciona e onde escreve, sempre à mão, com a letra miúda, seus versos e "todas as besteiras que penso quando me fecho aqui". (Barros, 1997)

Dizem que são muitos - incontáveis - os rascunhos do poeta. Pertencem à experiência intima de sua escrita. Não é um espaço qualquer, folhas de papel branco são cuidadosamente dobradas e recortadas em quatro partes, reunidas em maços, recebendo capas, algumas vezes feitas com cartões postais, outras vezes com imagens, ou mesmo com desenhos. A mão, a lápis, sempre pela manhã, sozinho em seu escritório, eis parte da esfera dos múltiplos gestos da escrita do poeta, inventando e guardando os versos que mais tarde comporão seus livros: "Não gosto de aprender novidades. Só quero repisar nos termos repisados"(Barros, 1992). Aqueles que já tiveram em mãos esses bloquinhos não puderam 1ê-1os; apenas tocá-1os. 0 poeta prefere-os junto a si, velados.

Partes de seus cadernos, entretanto, terminam por chegar ao espaço público dos livros: certos versos, sempre que cantam; palavras desacostumadas; e, mais raramente, poemas inteiros. É sabido que Barros usa freqüentemente o procedimento da bricolage. Mas, além disso, algo mais requer espaço nos livros - e, aqui, 


\section{EM TESE}

Belo Horizonte, v. 5, p. I-305, dez. 2002

pensamos na marca da exigência de sua escrita íntima: o repisar, que, então, converte-se no gesto concreto de rascunhar.

A própria composição de muitos dos poemas de Barros incita-nos à idéia do rascunho. A utilização de versos prosaicos, de construções coloquiais, incorporações de falas e de sintaxe popular, a preferência por compor usando frases, o enfraquecimento das conexões, o uso estilístico "dos desvios semânticos, sintáticos e morfológicos e de dissonâncias lexicais" (Rezende, 1997) - esses são traços da escrita de Barros que nos retiram a certeza de estarmos lendo textos definitivos:

1.

Gravata de urubu não tem cor.

Fincando na sombra um prego ermo, ele nasce.

Luar em cima de casa exorta cachorro.

Em perna de mosca salobra as águas cristalizam.

Besouros não ocupam asas para andar sobre fezes.

Poeta é um ente que lambe as palavras e depois se alucina.

No osso da fala dos loucos há lírios. (Barros, 1996: 289)

Parece-nos que não existe, nesse canto 1 do poema "Seis ou treze coisas que eu aprendi sozinho", uma rigidez em sua composição formal que nos induziria a lê-10 como uma estrutura fixa no tempo, acabada, estabelecida. É como se, estando ainda antes do fim, convidassem-nos a imaginar variações em sua forma, como, por exemplo, a variação da seqüência dos versos. Isso porque os versos têm seu lugar preciso, estão ali e veiculam efeitos poéticos, mas parecem poder estar ali de maneira diferente - como o próprio título enuncia: são seis ou treze as coisas.

Se no tranco do vento a lesma treme, no que sou de parede a mesma prega; se no fundo da concha a lesma freme, aos refolhos da carne ela se agrega; se nas abas da noite a lesma treva; no que de mim jaz de escuro ela se trava; se no meio da náusea a lesma gosma, no que sofro de musgo a cuja lasma; se no vinco da folha a lesma escuma, nas calçadas do poema a vaca empluma! (Barros, 1996: 252)

Nesse poema, a estrutura engenhosa da composição traz-nos a impressão de que aí chegou-se ao fim. Entretanto, esses poemas formalmente mais bem acabados 
não se impõem nos livros de Barros. É a exigência de sua escrita $\frac{3}{4}$ repisar os termos $\frac{3}{4}$ e a sua experiência íntima de escrever $\frac{3}{4} O$ campo dos mínimos $e$ incontâveis bloquinhos $\frac{3}{4}$ que estabelecem e autorizam a inquietante verdade dessa poética:

\section{$(\ldots)$}

Melhor para chegar a nada é descobrir a verdade.

0 artista é um erro da natureza. Beethoven foi um erro perfeito.

Por pudor sou impuro.

0 branco me corrompe.

A minha diferença é sempre menos.

Palavra poética tem que chegar ao grau de brinquedo para ser séria.

Não preciso do fim para chegar.

Do lugar onde estou já fui embora. (Barros, 1996: 70-71)

Assim, é possível supor que o procedimento da repetição instaura 0 espaço propriamente literário nos livros de Manoel de Barros. Suas marcas fazem-se visiveis, por vezes, de maneira caprichosa, por vezes, de maneira indomável, nas formas de conteúdo e de expressão das quais se serve sua poética:

Noto que meus imitadores são melhores que eu. A imitação é mais requintada que a autenticidade em estado bruto. Estou com a impressão de que ando me imitando um pouco. 0 pior plágio é o que se faz de si mesmo. (Lispector, 1999: 36)

Nessa dimensão paradoxal (indomáve1), à qual a personagem "Autor" do livro Um sopro de vida parece fazer referência, quando abriga, em um mesmo plano, sem oposição, o requintado e o que há de pior, pensamos estar imbricada a força, talvez, dessas escritas de si, cuja repetição faz-se, também, por meio do recurso espúrio de plagiar a si mesmo. Reencontrando-nos, aqui, com o escrever de mau a pior, com a afirmação da errância e com os descaminhos de infinita deserção - Não preciso do fim para chegar. Do lugar onde estou já fui embora -, reencontra-nos o infinito literário: 


\section{EM TESE}

Belo Horizonte, v. 5, p. I-305, dez. 2002

0 erro e 0 facto de se estar a caminho sem jamais poder parar transformam 0 finito em infinito. Ao que se acrescentam estes traços especiais: apesar de o finito ser fechado, é sempre possível esperar sair dele, enquanto que a infinita vastidão, por ser sem saída, é prisão; do mesmo modo que todo 0 lugar absolutamente sem saída se torna infinito. 0 lugar do descaminho ignora a linha reta; nunca se vai de um ponto a outro ponto; não se parte daqui para chegar ali; nenhum ponto de partida e nenhum começo para a caminhada. Antes de se ter começado, já se está a recomeçar; antes de se ter terminado, repisa-se; esta espécie de absurdo que consiste em regressar sem nunca ter partido, ou em começar por recomeçar, é o segredo da "má" eternidade, correspondente à "má" infinitude, e talvez uma e outra encerrem o sentido do devir. (Blanchot, 1984: 104)

A poética de Barros acolhe, em um incessante movimento, a primeira pessoa: "seja quando o poema deixa falar o eu poético, seja quando o poeta cita seus próprios versos de obras anteriores, seja quando o nome próprio do autor se assina em idioleto manoelês archaico" (Castello Branco, 1996) e descobre, assim, os seus próprios meios literários para abrir acesso ao infinito no quarto fechado do sujeito: "Ora, onde há um duplo perfeito" (um plágio perfeito?), "o original apagase, e até a origem" (Blanchot, 1984: 105).

ABSTRACT :

This essay aims at reading the work of Manoel de Barros, having as theoretical support the reflections of Blanchot on the literary experience, taking as starting point the first work published by the poet in 1937 and arriving at his most recent published work, in 2000.

KEY WORDS: poetry, style, literary experience. 
BARROS, Manoel de Barros. In: EDITORIA MAIS. Os cadernos miúdos. In: Folha de São Paulo, $21 \mathrm{dez}$. 1997. (Mais!). BARROS, Manoel de. Folha de São Paulo, 15 jan. 1992. BARROS, Manoel de. Gramática expositiva do chão. Rio de Janeiro: Civilização Brasileira, 1996.

BARROS, Manoel de. Livro sobre nada. Rio de Janeiro: Record, 1996.

BLANCHOT, Maurice. O livro por vir. Trad. Maria Regina Louro. Lisboa: Relógio d'Água, 1984.

CASTELLO BRANCO, Lucia. In: Livro sobre nada. Rio de Janeiro: Record, 1996.

CASTELLO BRANCO, Lucia. Quase palavra. In: Nunca mais. Rio de Janeiro: Record, 2000.

LISPECTOR, Clarice. Para não esquecer. Rio de Janeiro: Rocco, 1999.

MATOS, Claudia Neiva de. Sinfonia do pântano. Jornal do Brasil, $17 \mathrm{fev}$. 1992.

RESENDE, Maria Ângela. Memória e infância em Manoel de Barros: a construção de uma poética. 1997. Dissertação (Mestrado em Literatura Brasileira) - FALE/UFMG, Belo Horizonte.

SANCHES NETO, M. Manoel de Barros e Rubem Fonseca escrevem livros que são um retorno do mesmo. Gazeta de Curitiba, 21 dez. 1998. 